\title{
Workplace-based assessment for international medical graduates: at what cost?
}

\section{Balakrishnan (Kichu) R Nair AM, MD, FRACP, FRCP Director,' and Associate Dean² \\ Andrew M Searles BEc, MMedStats, PhD Health Economist \\ Rod I Ling $\mathrm{PhD}, \mathrm{MA}, \mathrm{BCom}$, Health Economist ${ }^{3}$ \\ Julie Wein \\ DipBus(Man) \\ Project Officer \\ Kathy Ingham \\ DipTraining\&Assess, \\ DipPractMgt, DipBus, \\ Centre Manager \\ 1 Centre for Medical Professional Development Hunter New England Local Health District. Newcastle, NSW. \\ 2 School of Medicine and Public Health University of Newcastle Newcastle, NSW. \\ 3 Hunter Medical Research Institute University of Newcastle Newcastle, NSW. \\ kichu.nair@ \\ newcastle.edu.au}

MJA 2014; 200: 41-44 doi: 10.5694/mjal3.10849

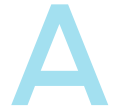

ustralia, like many developed countries, has a shortage of doctors. While this is disputed by some, ${ }^{1}$ the literature highlights current and projected shortages of skilled clinicians relative to the demand..$^{2-15}$ One response to this imbalance is to utilise international medical graduates (IMGs).

The Medical Board of Australia is responsible for the registration of all doctors in Australia and sets the relevant standards, codes and guidelines. The Australian Medical Council (AMC) oversees assessment before this. Doctors who have trained overseas can take one of two paths to registration. Those who attained medical qualifications in selected countries (United Kingdom, United States, Canada, New Zealand and Ireland) can fast-track registration under a competent authority pathway. IMGs who obtained their medical accreditation in other countries follow a standard pathway. ${ }^{16}$ In the standard pathway, proficiency is assessed by a 3.5-hour, computer-based, multiple choice examination and an integrated multidisciplinary structured clinical assessment. Clinical skills in medicine, surgery, obstetrics, gynaecology, paediatrics and psychiatry are assessed at 16 stations using role-players and one or two real patients. Candidates have 2 minutes of reading time and 8 minutes to complete the task at each station. A

\section{Abstrac}

Objective: To estimate the cost of resources required to deliver a program to assess international medical graduates (IMGs) in Newcastle, Australia, known as the Workplace Based Assessment (WBA) Program.

Design and setting: A costing study to identify and evaluate the resources required and the overheads of delivering the program for a cohort of $15 \mathrm{IMGs}$, based on costs in 2012.

Main outcome measures: Labour-related costs.

Results: The total cost in 2012 for delivering the program to a typical cohort of 15 candidates was $\$ 243384$. This equated to an average of $\$ 16226$ per IMG. After allowing for the fees paid by IMGs, the WBA Program had a deficit of $\$ 153384$, or $\$ 10226$ per candidate, which represents the contribution made by the health system.

Conclusion: The cost per candidate to the health system of this intensive WBA program for IMGs is small.

pass requires satisfactory performance in 12 or more stations, including one obstetrics and gynaecology station and one paediatrics station.

The waiting period to sit for the structured clinical assessment is long, and often fewer than half of the candidates are successful. ${ }^{9,17}$ Combined with a low pass rate, this restricts employment and subsequent opportunities for many IMGs. From an IMG's perspective, the traditional examinations provide a very limited opportunity to understand and be integrated into the Australian health care system.

Evidence suggests that this traditional pathway for registering and integrating IMGs into the Australian health care system has not been ideal. A recent study found that IMGs are more likely than Australian-trained doctors to have complaints made against them to medical boards. ${ }^{18}$ The medical boards in Australia have also been more likely to make adverse findings against IMGs than against Australian-trained doctors. ${ }^{18}$ The authors of this study suggested a rethink on the regulation of IMGs in Australia. A logical starting place for reviewing this would be at the start of the IMGs' journey.

The Workplace Based Assessment (WBA) Program was developed in 2010 by a team of academics from Hunter New England Health (HNEH) and the University of Newcastle (UN) to overcome some of the difficulties associated with assessing IMGs and integrating them into the health care

\section{Outline of the pathway for international medical graduates in the Workplace Based Assessment Program*17}

\section{Program element}

Twelve mini clinical evaluation exercises

Seven case-based discussions

Two in-training assessments

Multisource feedback ( $360^{\circ}$ assessment): formative then summative

\section{Requirements}

Minimum requirement: pass $8 / 12$ (at least one exercise in each discipline)

Minimum requirement: pass 4/7 (one patient; three paper-based cases)

Both must reflect performing "at expected level"

"Satisfactory" grade for summative assessment
Disciplines and areas assessed

Medicine: management and prescribing; physical examination

Surgery: management; physical examination

Emergency medicine: history and investigation; management

Mental health: history; management and counselling

Paediatrics: history; counselling and patient education Obstetrics and gynaecology: investigations and diagnosis; management and prescribing/counselling

2 patient cases in own discipline

5 paper-based cases in other discipline

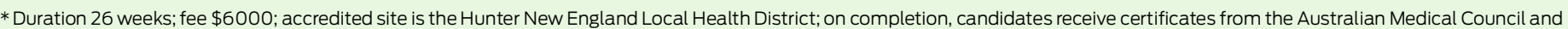
apply to the Medical Board of Australia for registration. 
system. It was accredited by the AMC in 2010 as an alternative to the AMC clinical examination and to give an opportunity to study its feasibility. The WBA Program is based on a 6-month assessment process. Entry into the WBA Program has the same eligibility requirements as the standard pathway, including verification of qualifications and passes in the AMC English language test and the multiple choice exam. However, the WBA candidates have limited medical registration to work in accredited Australian hospitals. ${ }^{9}$ Details of the program have been reported previously, ${ }^{17}$ and are summarised in Box 1 . A recent parliamentary enquiry recommended a national rollout. ${ }^{9}$

Health system resources provided by HNEH and UN to deliver the program include:

- 91 assessors from medicine, surgery, paediatrics, obstetrics and gynaecology, mental health, emergency and general practice;

- academics to conduct calibration and recalibration of assessors;

- administrative staff to support and coordinate the program;

- staff members for the program committees (governance committee; appeals committee; $360^{\circ}$ review panel); and

- the Director of the program.

Our aim in this study was to report an estimate of the resources required to deliver the WBA Program from the perspective of the health care system.

\section{Methods}

We assessed 2012 costs by stipulating:

- the resources considered appropriate for inclusion in the costing;

- the measurement of these resources;

- how monetary units were applied. ${ }^{19}$

The costing in this study reflects the direct and indirect resources required to deliver the program to a cohort of 15 IMGs - the average number of candidates per cohort in the WBA Program over 2010-2012.

\section{Cost inclusions and exclusions}

Resources included in the costing were those directly expended, compensated for or forgone by HNEH or UN to deliver the program. Costs included administrative labour to organise and deliver the program; participation of assessors and academics in program delivery, assessment and governance; and consumables.

The time spent by candidates was excluded. Some assessments were conducted in candidates' own time and some occurred during IMGs' regular working hours. IMGs were instructed that their assessment was not to interfere with their work or impact on their colleagues, and any lost time had to be made up.

The costing did not explicitly include allowances for capital, depreciation or rental values for the use of $\mathrm{HNEH}$ or UN fixed assets such as lecture theatres used to deliver some aspects of the program. However, an overhead of $30 \%$ applied to the cost of labour was assumed to cover these and other indirect costs. The research and initial setup expenses for designing the program were also excluded.

\section{Quantifying resources}

The measurement of the quantity of resources relied on a mapped pathway of the program (Box 2). The map identified five major stages of activity. Other sources included administrative documents, interviews with recent candidates, staff and assessors and observation of induction and feedback sessions.

Consumables formed a relatively small component of the resources and included an allowance for all program documentation.

\section{Monetary units}

Monetary values, in Australian dollars, were applied to the quantity of resources used in the delivery of the WBA Program. We aimed to base costs on opportunity cost, which is the value of activity forgone because of the resources committed to the program. Market price is an appropriate proxy for the opportunity cost of the resource. ${ }^{20}$ Four levels of labour were recognised (Box 3):

- Administrative activities of a health manager. $^{21}$

- Administrative activities in support roles (eg, support at workshops such as the information session and graduation), costed as administration officers. $^{22}$

- Clinicians providing assessment, feedback, involvement with committees etc, costed as staff specialists. ${ }^{23}$
- Executive staff providing services for assessments, feedback, time on committees, governance and presentations at workshops, costed as senior staff specialists plus a special academic allowance. $^{23}$

Among assessors the true hourly rate is likely to differ depending on variables such as medical specialty, length of service and individual contracts. Therefore, the valuation we used represented assessors from a range of clinical backgrounds.

\section{Results}

The total labour-related cost of delivering the WBA Program for a cohort of 15 IMGs was $\$ 240236$. After adding consumables $(\$ 3148)$, the per candidate cost was $\$ 16226$. Labour costs comprised $98.7 \%$ of total costs.

The analysis allowed for the examination of cost by program stage, cross-tabulated by activity (Box 4). The most resource-intensive stage was program delivery (\$190566). Of this amount, \$176 027 was for assessment. Major cost components for assessment were mini clinical evaluation exercises (\$122691) and casebased discussions (\$43396).

Revenue collected by the WBA Program was $\$ 6000$ per candidate, totalling $\$ 90000$. After receipt of fees, the program had a deficit of $\$ 153384$ (\$10226 per candidate).

\section{Discussion}

Based on our cost analysis, the WBA Program for IMGs had a deficit of \$153384 (\$10226 per candidate), which represents the contribution made by the health care organisation.

This investment has produced several positive outcomes. Out of 95 IMG candidates who have undertaken the program, all have passed. Therefore, compared with the structured clinical assessment and its approximate 50\% pass rate, the program maximises the possible supply of well prepared and assessed IMGs into the Australian medical workforce.

The program provides an extended window for observing and assessing IMGs and allows a rigorous assessment process by a range of senior clinicians who take ownership of the program and provide assessment. From the assessors' perspective, it gives them an 
2 Schematic of the Workplace Based Assessment (WBA) Program for international medical graduates

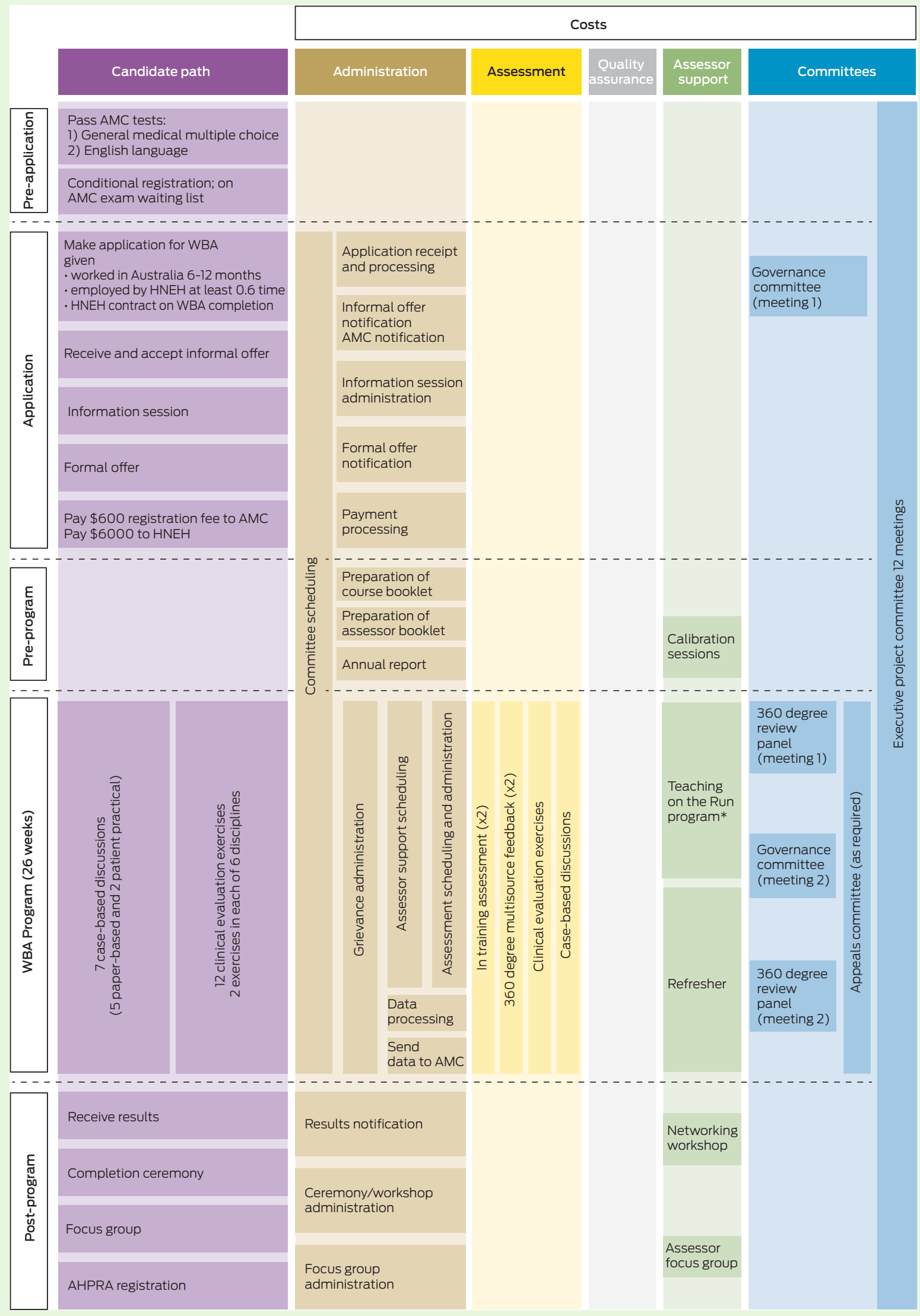

AHPRA = Australian Health Practitioner Regulation Agency. AMC = Australian Medical Council. $\mathrm{HNEH}=$ Hunter New England Health. $*$ National program for doctors and medical educators, aimed at improving the quality of the teaching and supervision of trainee doctors and students. 
3 Estimated hourly labour costs, including overheads, 2012

\begin{tabular}{lcc} 
Staff type & $\begin{array}{c}\text { Hourly } \\
\text { rate }\end{array}$ & $\begin{array}{c}\text { Hourly rate } \\
\text { including } \\
\text { overheads }\end{array}$ \\
\hline $\begin{array}{l}\text { Administration } \\
\text { (manager) }\end{array}$ & $\$ 31.82$ & $\$ 41.37$ \\
$\begin{array}{l}\text { Administration } \\
\text { (support) }\end{array}$ & $\$ 22.90$ & $\$ 29.77$ \\
$\begin{array}{l}\text { Assessor (clinical) } \\
\begin{array}{l}\text { Executive (senior } \\
\text { clinical) }\end{array}\end{array}$ & $\$ 104.86$ & $\$ 136.32$ \\
& & $\$ 137.10$
\end{tabular}

opportunity to observe clinical performance and workplace interaction. From the candidates' perspective, there is a 6month period to learn to work within the Australian health care system.

Although the program does not provide training, regular feedback allows candidates to self-assess, self-correct and reflect as needed. Successful integration of IMGs into the health care system is not solely based on clinical expertise; it requires the individual to appropriately interact and communicate with patients and staff. This is a core component of the program and is assessed through the multisource feedback from co-workers at all levels of the health system who would otherwise not routinely be invited to comment.

The program helps to offset the cost of recruiting doctors for health services, as the candidates are retained in the settings in which they have worked while gaining registration. Over the long term, IMGs who successfully complete the WBA Program may provide benefits to the Australian health care system during their working lifetime. In this context, the cost of the program to the health system is relatively small.

Projections indicate that the supply of doctors in Australia is likely to fall short of demand until at least 2025, suggesting IMGs will remain an important source of skilled clinicians in this country. ${ }^{24}$ The WBA Program can be delivered in regional Australia (where there are substantial doctor shortages). It makes good sense to ensure that IMGs seeking registration in Australia are provided with an efficient and fair opportunity to register.

As a preliminary study to describe the costs associated with delivering the WBA Program from the perspective of the health system, our analysis had some limitations. The study captured some costs that did not create a monetary burden for the health system, and it might appear that this would create an upward bias in our estimates. For example, there was evidence that assessors and administrative staff contributed unpaid time to the program. However, we had aimed to capture opportunity cost, and this rightly includes the unpaid overtime spent on the program because it represents time that could have been spent on other health service functions.

We have identified the resources used to deliver the program, and yet it is up to health system administrators to determine whether this investment represents value for money. Our study was not designed to examine the effectiveness of the program nor to compare its cost against benefit. Further work is being planned to compare the cost and effectiveness of the program against the standard pathway.

Our program constitutes an innovative response to improving the assessment pathway for IMGs and we have now shown that the cost per candidate for the program is small. IMGs who have their performance assessed in the workplace and receive longer-term, constructive feedback will benefit the health care system. We believe this program is cost-effective and the cost is a small price to pay for doctors who will provide many years of safe and effective service.
Competing interests: No relevant disclosures.

Received 24 Jun 2013, accepted 19 Aug 2013.

1 Birrell B. Too many GPs. Melbourne: Centre for Population and Urban Research, Monash University, 2013. http://artsonline.monash.edu. au/cpur/too-many-gps (accessed Sep 2013).

2 Australian Government Productivity Commission. Australia's health workforce. Canberra: Commonwealth of Australia, 2005. http://www. pc.gov.au/projects/ study/health-workforce/docs/finalreport (accessed Sep 2013).

3 Health Workforce Australia. Health workforce 2025: medical specialties. Vol. 3. Canberra: HWA, 2012. http://www.hwa.gov.au/sites/uploads/HW2025_V3_ FinalReport20121109.pdf (accessed Sep 2013).

4 Birrel RJ. Australian policy on overseas-trained doctors. Med J Aust 2004; 181: 635-639.

5 Bloor K, Hendry V, Maynard A. Do we need more doctors? J R Soc Med 2006; 99 : 281-287.

6 Buchan JM, Naccarella L, Brooks PM. Is health workforce sustainability in Australia and New Zealand a realistic policy goal? Aust Health Rev 2011; 35: 152-155.

7 Gorman DF, Brooks PM. On solutions to the shortage of doctors in Australia and New Zealand. Med J Aust 2009; 190: 152-156.

8 Harris MF, Zwar NA, Walker CF, Knight SM. Strategic approaches to the development of Australia's future primary care workforce. Med J Aust 2011; 194: S88-S9l.

9 House of Representatives Standing Committee on Health and Ageing. Lost in the labyrinth: report on the inquiry into registration processes and support for overseas trained doctors. Canberra: Parliament of Australia, 2012 http://www.aph.gov.au/parliamentary_business/committees/house_of representatives_committees?url=haa/overseasdoctors/report.htm (accessed Sep 2013).

10 Iredale R. Luring overseas trained doctors to Australia: issues of training, regulating and trading. Int Migr 2009; 47: 31-65. doi: 10.1111/.j.1468-2435.2009.00563.x.

11 Joyce CM, McNeil JJ. Participation in the workforce by Australian medical graduates. Med Educ 2006; 40: 333-339.

12 Kamalakanthan A, Jackson S. The supply of doctors in Australia: is there a shortage? Discussion paper no. 341. Brisbane: School of Economics, University of Queensland, Queensland, 2006. http://www.uq.edu.au/economics/abstract/341.pdf (accessed Sep 2013).

13 Kamalakanthan A, Jackson S. Doctor supply in Australia: rural-urban imbalances and regulated supply. Aust J Prim Health 2009; 15: 3-8. doi: 10.1071/PY08055.

14 Maynard A. Medical workforce planning: some forecasting challenges. Aust Econ Rev 2006; 39: 323-329. doi: 10.1111/.1.1467-8462.2006.00422.x.

15 Schofield DJ, Fletcher SL, Callander EJ. Ageing medical workforce in Australia - where will the medical educators come from? Hum Resour Health 2009: 7: 82

16 Medical Board of Australia. International medical graduates. Standard pathway. http://www. medicalboard.gov.au/Registration/International-Medical-Graduates/ Standard-Pathway.aspx (accessed Apr 2013).

17 Nair BR, Hensley MJ, Parvathy MS, et al.

A systematic approach to workplace-based assessment for international medical graduates. Med J Aust 2012; 196: 399-402.

18 Elkin K, Spittal MJ, Studdert DM. Risks of complaints and adverse disciplinary findings against international medical graduates in Victoria and Western Australia. Med J Aust 2012; 197: 448-452.

19 Evans C, Crawford B. Direct medical costing for economic evaluations: methodologies and impact on study validity. Drug Inf J 2000; 34: 173-184.

20 Drummond MF, O'Brien B, Stoddart GL,

Torrance GW, editors. Methods for the economic evaluation of health care programmes. 2nd ed. Oxford: Oxford University Press, 1997.

21 Industrial Relations Commission of New South Wales. Health Managers (State) Award. 27 July 2012. (Publication No. C7866.)

22 Industrial Relations Commission of New South Wales. Health Employees' Administrative Staff (State) Award. 27 July 2012. (Publication No. C7873.)

23 Industrial Relations Commission of New South Wales. Staff Specialists (State) Award. 50ctober 2012. (Publication No. C7975.)

24 Health Workforce Australia. Health workforce 2025: doctors, nurses and midwives. Vol. 1. Canberra: HWA, 2012. http://www.hwa.gov.au/sites/uploads/FinalReport Volumel_FINAL-20120424.pdf (accessed Sep 2013).

\section{Labour-related costs* of the Workplace Based Assessment Program, by activity and program stage}

Program stage

\begin{tabular}{|c|c|c|c|c|c|c|}
\hline Activity & Pre-application & Application & Pre-program & Program delivery & Post-program & Total \\
\hline General administration & - & $\$ 734$ & $\$ 544$ & $\$ 2670$ & $\$ 710$ & $\$ 4658$ \\
\hline Assessment & - & - & $\$ 331$ & $\$ 176027$ & - & $\$ 176358$ \\
\hline Quality assurance & - & - & - & $\$ 1352$ & - & $\$ 1352$ \\
\hline Assessor support & - & - & $\$ 44926$ & $\$ 89$ & - & $\$ 45015$ \\
\hline Committees & $\$ 124$ & $\$ 248$ & $\$ 2053$ & $\$ 10428$ & - & $\$ 12853$ \\
\hline Total & $\$ 124$ & $\$ 982$ & $\$ 47854$ & $\$ 190566$ & $\$ 710$ & $\$ 240236$ \\
\hline
\end{tabular}

* Materials and function expenses of $\$ 3148$ excluded. 